\title{
Thoracoscopic carinal resection and reconstruction in a patient with mucoepidermoid carcinoma
}

\author{
Ryoichi Nakanishi, MD, PhD, ${ }^{\mathrm{a}}$ Toshihiro Yamashita, MD, ${ }^{\mathrm{a}}$ Kenji Muranaka, MD, ${ }^{\mathrm{b}}$ and

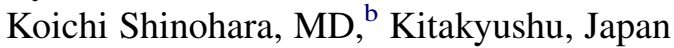

Video clip is available online.

Resection of any tumor that involves the carina requires a thoracotomy because of technical difficulties in airway management and carinal reconstruction. ${ }^{1}$ This report presents the first known case of thoracoscopic carinal resection and reconstruction in a patient with a carinal tumor.

\section{CLINICAL SUMMARY}

A 39-year-old woman rearing 2 children had hemoptysis. Radiologic images showed a carinal tumor without any other associated diseases (Figure 1). A transbronchial

From the Departments of Thoracic Surgery ${ }^{\mathrm{a}}$ and Anesthesiology, ${ }^{\mathrm{b}}$ Shin-Kokura Hospital, Federation of National Public Service, Personnel Mutual Aid Associations, Kitakyushu, Japan.

Disclosures: Authors have nothing to disclose with regard to commercial support.

Received for publication Sept 10, 2012; revisions received Nov 15, 2012; accepted for publication Dec 5, 2012; available ahead of print Jan 10, 2013.

Address for reprints: Ryoichi Nakanishi, MD, PhD, Department of Thoracic Surgery, Shin-Kokura Hospital, Federation of National Public Service, Personnel Mutual Aid Associations, Kanada 1-3-1, Kokurakita-ku, Kitakyushu, 803-8505, Japan (E-mail: ryoichi@med.uoeh-u.ac.jp).

J Thorac Cardiovasc Surg 2013;145:1134-5

$0022-5223 / \$ 36.00$

Copyright (c) 2013 by The American Association for Thoracic Surgery

http://dx.doi.org/10.1016/j.jtcvs.2012.12.008
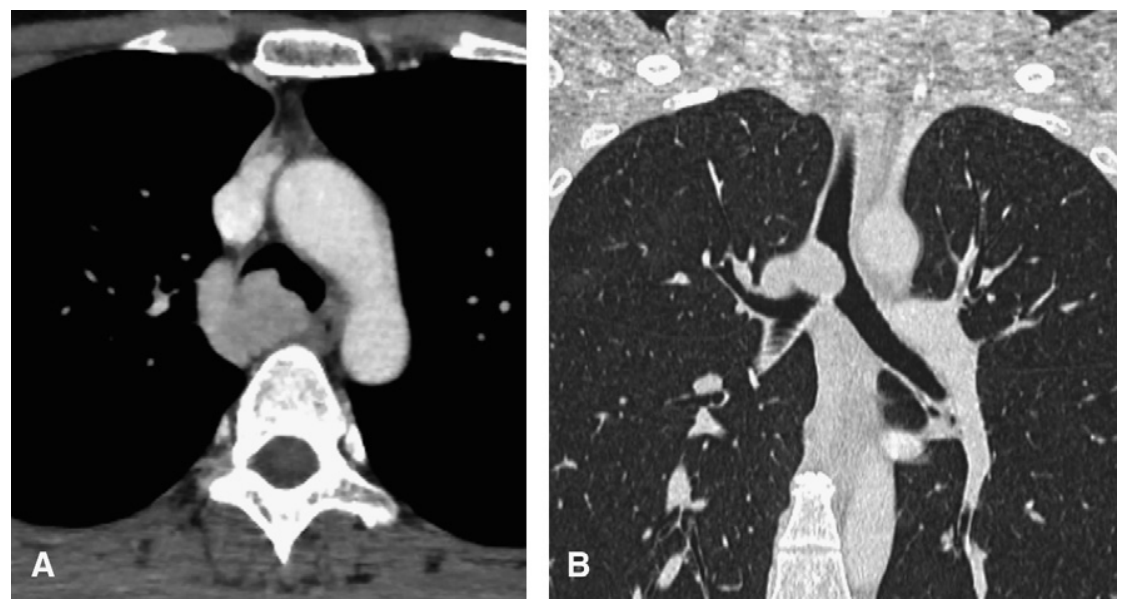

FIGURE 1. Computed tomographic scans of the chest showing an abnormal mass approximately $2.6 \mathrm{~cm}$ in diameter involving the carina. A, Axial view. $\mathrm{B}$, Coronal view.

biopsy revealed carcinoma. Thoracoscopic surgery was planned to allow the patient an early return to her normal life.

One-lung ventilation was established using an endobronchial blocker tube. Thoracoscopic carinal surgery was begun while viewing only a video monitor, without rib spreading, through an access window measuring $4.0 \mathrm{~cm}$ in length that was placed in the third intercostal space on the anterior axillary line and 2 additional 1.2 -cm diameter ports placed in the sixth intercostal spaces on the auscultatory triangle and the midaxillary line. Hilar and mediastinal lymph node dissections were performed after division of the pulmonary ligament. The left main bronchus and the trachea were mobilized by blunt dissection. The traction 4-0 monofilament sutures of both the left bronchus and the trachea were extracted to the outside of the body using the Endo Close device (Tyco Healthcare, Norwalk, Conn) through the third and seventh intercostal spaces on the midaxillary line, respectively. The carina measuring $4.0 \mathrm{~cm}$ in length with the involved area was then removed with adequate margins that were pathologically negative for malignancy. Anastomosis between the trachea and the left bronchus was primarily performed in an end-to-end fashion with 3-0 absorbable monofilament sutures after reduction of the tension by drawing the traction sutures. The right main bronchus was then implanted below the first anastomosis in an end-to-side fashion. The anastomoses were 
mainly performed with running sutures. High-frequency jet ventilation (HFJV) was frequently performed via the lumen of the blocker tube with a deflated balloon placed in the left main bronchus during each anastomosis (Video 1). The jet ventilator (JP-1; Senko Co, Tokyo, Japan) delivered $100 \%$ oxygen with a respiratory rate of $2 \mathrm{~Hz}$, a working pressure of 1.00 to $1.25 \mathrm{kgf} / \mathrm{cm}^{2}$, and an inspiratory time of $25 \%$. The vital signs were maintained and pulse oximetry confirmed that oxygen saturation was normal during HFJV. A blood gas analysis showed arterial carbon dioxide tension ranging from 29.4 to $34.2 \mathrm{~mm} \mathrm{Hg}$. Each anastomosis was confirmed to have no air leaks. There were no intraoperative problems. The patient was extubated at the end of the operation and was sent to the recovery ward. The patient was kept in a position of head anteflexion until the first postoperative week and her neck extension was restricted during the next week. During 2 weeks of hospitalization, the patient made an uneventful recovery. The patient was able to perform activities similar to her busy preoperative life immediately after hospital discharge. The final pathology report showed mucoepidermoid carcinoma with a negative surgical margin. The patient is well without any signs of recurrence at 12 months after surgery and the anastomoses showed good patency (Figure 2).

\section{DISCUSSION}

Airway management during carinal surgery includes several concerns about tube management without interfering with the surgical field and ventilation with favorable oxygenation. HFJV via the lumen of the blocker tube, which helped achieve 1-lung ventilation without causing any injury to the tumor, resolved such concerns without causing either hypercapnea or hypoxemia. ${ }^{2}$

Carinal reconstruction is associated with several concerns, including a reduction of anastomotic tension and types of the reconstruction and sutures, even in open procedures. ${ }^{1}$ The thoracoscopic carinal surgery is more complex. Effective traction using endoscopic devices was useful for reducing the anastomotic tension. The removal of longer segments of the airway and problems of ventilation required the technically demanding type of reconstruction. ${ }^{1}$ However, suturing the airway was not as difficult as was initially expected because a running suture was mainly used to both prevent any tangling of the sutures and reduce the number of ligations. The running suture, which is reliable in the tensile portion, has been experimentally certified to be a reliable procedure that can be used for tracheal anastomosis. ${ }^{3,4}$

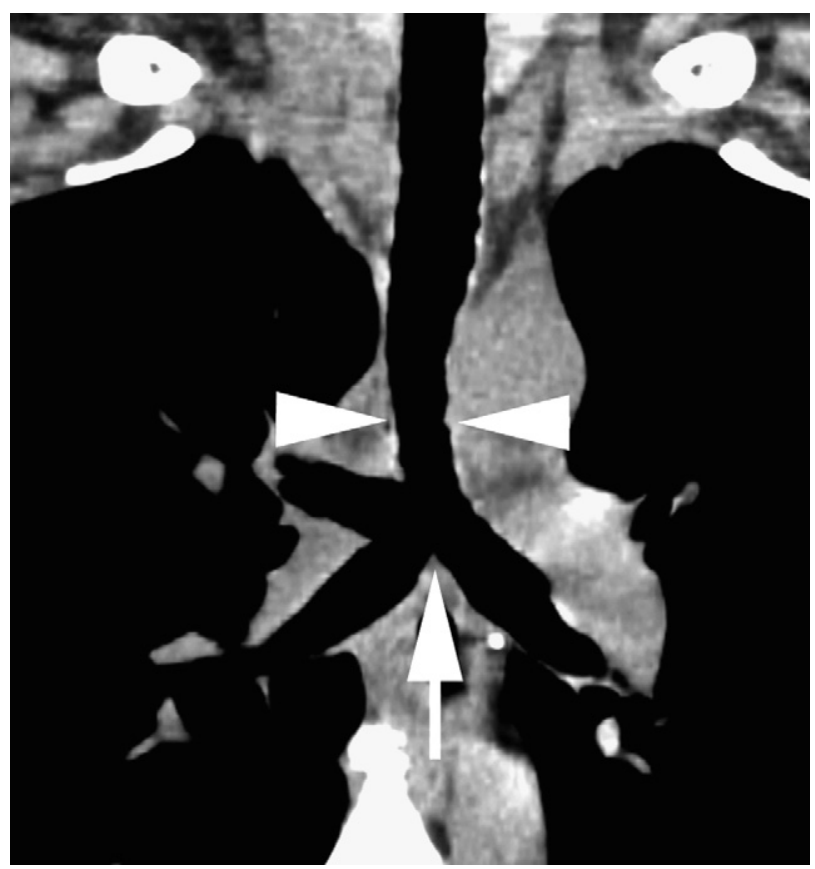

FIGURE 2. A computed tomographic scan of the chest showing the first (arrowheads) and the second (arrow) anastomoses to have good patency.

The benefits of thoracoscopic surgery over thoracotomy for such a complicated procedure include fewer postoperative complications and an earlier return to full preoperative activities. ${ }^{5}$ Thoracoscopic carinal resection and reconstruction was feasible in this patient with good clinical outcomes, including the benefits described above. HFJV using a blocker tube, effective traction using endoscopic devices, and the extensive use of running sutures thus allowed the surgeons to perform thoracoscopic carinal surgery in a patient with mucoepidermoid carcinoma.

\section{References}

1. Mitchell JD, Mathisen DJ, Wright CD, Wain JC, Donahue DM, Moncure AC, et al Clinical experience with carinal resection. J Thorac Cardiovasc Surg. 1999;117: 39-52.

2. Chin JH, Lee EH, Choi DK, Choi IC. High frequency jet ventilation of one lung using a bronchial blocker of Univent during carinal resection. J Korean Med Sci. 2010;25:1083-5.

3. Poole GV Jr, Meredith JW, Kon ND, Martin MB, Kawamoto EH, Myers RT. Suture technique and wound-bursting strength. Am Surg. 1984;50:569-72.

4. Nakanishi R, Shirakusa T, Mitsudomi T. Maximum length of tracheal autografts in dogs. J Thorac Cardiovasc Surg. 1993;106:1081-7.

5. Nakanishi R, Fujino Y, Oka S, Odate S. Video-assisted thoracic surgery involving major pulmonary resection for central tumors. Surg Endosc. 2010; $24: 161-9$ 